\title{
Comparison of Steroid Treatment with and without Hyperbaric Oxygen Therapy for Idiopathic Sudden Sensorineural Hearing Loss
}

\author{
Abitter Yücel ${ }^{1}$ and Yaşar Özbuğday ${ }^{2}$ \\ ${ }^{1}$ Department of Otorhinolaryngology Head and Neck Surgery, Konya Health Application and Research Center, \\ University of Health Sciences Turkey, Konya, Turkey \\ ${ }^{2}$ Department of Otorhinolaryngology Head and Neck Surgery, Konya Training and Research Hospital, \\ University of Health Sciences Turkey, Konya, Turkey
}

Received December 12, 2019

Revised January 17, 2020

Accepted February 21, 2020

Address for correspondence
Abitter Yücel, MD
Department of Otorhinolaryngology
Head and Neck Surgery,
Konya Health Application and
Research Center,
University of Health Sciences,
Yeni Meram Street No:97 Meram,
Konya, Turkey
Tel +90 5052677146
Fax +90332 2210000
E-mail abitteryucel@hotmail.com

Background and Objectives: In this study, we compared the outcomes of patients with idiopathic sudden sensorineural hearing loss who underwent steroid treatment with or without hyperbaric oxygen (HBO) therapy and were followed-up in our clinic. Subjects and Methods: Patients were divided into two groups according to their treatment regimen. Steroid group received intravenous $1 \mathrm{mg} / \mathrm{kg}$ methylprednisolone which was due to be completed in 2-3 weeks with decreasing doses, and five doses of $0.5 \mathrm{~mL}$ intratympanic dexamethasone. Steroid+HBO group received the same steroid treatment with the addition of HBO therapy. The audiologic results of both treatment groups were compared after considering the patients' risk factors. Results: There was no significant difference between the steroid and Steroid+HBO groups in terms of hearing gain and degree of recovery, both at all degrees of hearing loss, and in severe and profound hearing loss. Hearing gain was similar when evaluated by audiogram type and admission time in both treatment groups. Conclusions: We found that the addition of HBO therapy to systemic plus intratympanic steroid treatment did not affect hearing gain at all degrees of hearing loss in this study. Furthermore, audiogram type and admission time did not affect hearing gain between the two groups.

J Audiol Otol 2020;24(3):127-132

KEY WORDS: Sudden sensorineural hearing loss · Steroid · Hyperbaric oxygen therapy.

\section{Introduction}

Idiopathic sudden sensorineural hearing loss (ISSNHL) is defined as sensorineural hearing loss that develops in 3 days or less, at 3 consecutive frequencies based on pure tone audiometry (PTA) [1]. Despite its clear definition, there is no consensus on its etiology and treatment. A specific cause is identified in only $10 \%$ of cases [2]. Viral infections, circulatory disorders, labyrinth membrane rupture, autoimmune reactions, metabolic dysfunction, and the production of toxic substances are among the leading etiologies [3,4]. The treatment

This is an Open Access article distributed under the terms of the Creative Commons Attribution Non-Commercial License (https://creativecommons.org/licenses/by-nc/4.0/) which permits unrestricted non-commercial use, distribution, and reproduction in any medium, provided the original work is properly cited. modalities are also very varied due to such different etiologies. Vasodilators, systemic and topical steroids, antiviral agents, vitamins, anticoagulants, hemodilution, prostacyclin, ganglion blockade, and hyperbaric oxygen (HBO) therapy have been the most recently used agents for the treatment of ISSNHL $[5,6]$. In clinical practice, steroids are the most commonly used treatment [7].

In our clinical practice, intravenous (IV) and intratympanic (IT) steroids are used as the first choice for the treatment of ISSNHL. In addition, since our center has a HBO therapy unit, patients also benefit from HBO therapy frequently. We attempted to evaluate the contribution of HBO therapy to systemic and IT steroid treatment by considering patients prognosis and risk factors. In this study, we compared the outcomes of ISSNHL patients who underwent treatment with or with- 
out HBO therapy who were followed up in our clinic.

\section{Subjects and Methods}

\section{Patients}

The files of patients aged 10 years and over who were diagnosed and treated for ISSHL in our clinic between 2016 and 2018 were reviewed retrospectively. Patients with unilateral sudden onset of 30 decibel $(\mathrm{dB})$ or more sensorineural type hearing loss, an unknown cause of hearing loss, less than 30 days between the onset of hearing loss and the onset of treatment, and patients without fluctuating hearing loss were included in this study.

Patients with a history of otological surgery and ototoxic drug use, acoustic trauma and barotrauma, genetic sensorineural hearing loss, and patients with evidence of retrocochlear disease on magnetic resonance imaging were excluded from the study. Information on patient characteristics such as age, sex, PTA tests after the admission and treatment (1-3 months), degree of hearing loss, type of audiometry (descending, ascending, flat, and bowl), and duration of treatment ( $0-3$, 4-10, >10 days) were recorded.

\section{Treatment protocols}

Patients were divided into two groups according to the treatment regimen. The first group (Steroid group) received IV $1 \mathrm{mg} / \mathrm{kg}$ methylprednisolone (Precort-Liyo 40 mg, KoçakFarma, İstanbul, Turkey) which was due to be completed in 2-3 weeks with decreasing doses, and five doses of $0.5 \mathrm{~mL}$ IT dexamethasone (İnfladox $8 \mathrm{mg} / 2 \mathrm{~mL}$, My Farma Drug Industry, İstanbul, Turkey).The second group (Steroid+HBO group) received the same steroid treatment in addition to HBO therapy. Each HBO therapy session was performed at 2 atmospheres absolut (ATA) for 1 hour, with a total of 20 sessions daily, excluding weekends. IT and IV steroid treatment was started simultaneously in both patient groups.

\section{Assessment of hearing gain}

All patients were evaluated by a PTA test at frequencies of 250-6,000 Hertz $(\mathrm{Hz})$ before and after treatment. PTA was evaluated by calculating the average of the hearing thresholds at 500, 1,000, 2,000, 4,000 Hz during each audiometry test. Audiometry tests performed between 1 and 3 months after treatment were considered. Improvement in hearing was evaluated by two methods. First, hearing gain was calculated by subtracting the pretreatment PTA value from posttreatment PTA value. In the second method, Clinical Practice Guideline: Sudden Hearing Loss, American Academy of Otolaryngology-Head and Neck Surgery (AAO-HNS Criteria)
[8] was taken into consideration. Complete recovery was considered if the follow-up PTA (dB HL) or speech recognition threshold (SRT) (dB HL) improved to within $10 \mathrm{~dB}$ of the pre-sudden hearing loss hearing level. Partial recovery was considered if the follow-up PTA (dB HL) or SRT (dB HL) improved to within $50 \%$ of the pre-sudden hearing loss hearing level. No recovery was considered if the follow-up PTA (dB $\mathrm{HL}$ ) or SRT (dB HL) was less than $50 \%$ of the pre-sudden hearing loss hearing level.

\section{Compliance with ethical standards}

Approval was obtained from the Ethics Committee of the local University for this study (No: 2019/1730).

\section{Statistical analysis}

Descriptive statistics were used to compare the general characteristics of all participants. Test of Normality, including Kolmogorov-Smirnov and Shapiro-Wilk tests, were used to determine the distribution of data. Data with normal distribution are presented as mean \pm standard deviation. Categorical variables are shown as a number (n). The comparison of the numerical data between groups and categorical variables was performed with the appropriate test such as the independent samples t-test, Mann-Whitney, chi-squared test, and Fisher'sexact test. Statistical Package for Social Sciences Windows software (ver. 22; IBM Corp., Armonk, NY, USA) was used for all statistical analyses. A $p$ value less than 0.05 was considered statistically significant.

\section{Results}

A total of 272 patients who were diagnosed with ISSNHL, were followed-up at our clinic, and whose files were fully accessible were included in this study. There were 194 patients in the Steroid + HBO group and 78 patients in the Steroid group. The mean age of the Steroid+HBO and Steroid groups were 48 and 46 years, respectively. The female/male ratio was 83/111 in the Steroid+HBO group and 31/47 in the Steroid group. There was no statistically significant difference between the two groups in terms of mean age and gender $(p<0.05)$. The pre- and post-treatment PTA levels were 65 and $43 \mathrm{~dB}$, respectively in both the Steroid $+\mathrm{HBO}$ and Steroid groups. There was no statistically significant difference between groups in terms of pre-treatment PTA values and hearing gains $(p>0.05)$ (Table 1). When the patients were evaluated according to the degree of recovery (AAO-HNS Criteria), there was no significant difference between the two groups in terms of all degrees of recovery $(p>0.05)$ (Table 2$)$. Table 2 shows the word reconstruction score (WRS), presence of vertigo, tinnitus, ciga- 
Table 1. Pre- and post-treatment PTA values and hearing gains of the groups at the beginning and end of treatment

\begin{tabular}{lccccc}
\hline Treatment groups & $\begin{array}{c}\text { Pre-treatment PTA } \\
\text { Mean } \pm \text { SD }(\mathrm{dB})\end{array}$ & $\begin{array}{c}\text { Post-treatment PTA } \\
\text { Mean } \pm \text { SD }(\mathrm{dB})\end{array}$ & p value & $\begin{array}{c}\text { Hearing gain } \\
\text { Mean } \pm \text { SD }(\mathrm{dB})\end{array}$ & $p$ value \\
\hline Steroid $(\mathrm{n}=78)$ & $64.53 \pm 3.07$ & $43.20 \pm 3.43$ & $<0.001^{*}$ & $21.33 \pm 2.08$ & \\
Steroid+HBO $(\mathrm{n}=194)$ & $64.58 \pm 1.65$ & $43.13 \pm 1.87$ & $<0.001^{*}$ & $21.11 \pm 1.58$ & $0.742^{\dagger}$ \\
\hline *Wilcoxon signed ranks test, ${ }^{\dagger}$ Mann-Whitney U test. PTA: pure tone average, HBO: hyperbaric oxygen &
\end{tabular}

*Wilcoxon signed ranks test, ${ }^{\dagger}$ Mann-Whitney U test. PTA: pure tone average, HBO: hyperbaric oxygen

Table 2. Distribution of recovery and demographic parameters of groups (AAO-HNS Criteria, 2012)

\begin{tabular}{|c|c|c|c|}
\hline Parameters & $\begin{array}{l}\text { Steroid group } \\
\qquad(n=78)\end{array}$ & $\begin{array}{l}\text { Steroid+HBO } \\
\text { group }(n=194)\end{array}$ & $\begin{array}{c}\mathrm{P} \\
\text { value }\end{array}$ \\
\hline $\mathrm{AAO}^{-H N S}$ Criterion ${ }^{\dagger}, \mathrm{n}(\%)$ & & & 0.219 \\
\hline Complete recovery & $34(43.6)$ & $63(32.5)$ & \\
\hline Partial recovery & $23(29.5)$ & $71(36.6)$ & \\
\hline No recovery & $21(26.9)$ & $60(30.9)$ & \\
\hline WRS & $59(67)^{*}$ & $58(61)^{*}$ & 0.884 \\
\hline Vertigo, n (\%) & & & 0.857 \\
\hline Yes & $25(32.1)$ & $60(30.9)$ & \\
\hline No & $53(67.9)$ & $134(69.1)$ & \\
\hline Tinnitus, n (\%) & & & 0.967 \\
\hline Yes & $42(53.8)$ & $105(54.1)$ & \\
\hline No & $36(46.2)$ & $89(45.9)$ & \\
\hline Cigarette, n (\%) & & & 0.700 \\
\hline Yes & $26(33.3)$ & $60(30.9)$ & \\
\hline No & $52(66.7)$ & $134(69.1)$ & \\
\hline Additional disease, n (\%) & & & 0.905 \\
\hline No & $53(67.9)$ & $128(66)$ & \\
\hline $\mathrm{HT}$ & $9(11.5)$ & $25(12.9)$ & \\
\hline $\mathrm{HL}$ & $4(5.1)$ & $14(7.2)$ & \\
\hline DM & $12(15.4)$ & $27(13.9)$ & \\
\hline
\end{tabular}

*median (interquartile range), ${ }^{\dagger}$ chi-square test. AAO-HNS: American Academy of Otolaryngology-Head and Neck Surgery, $\mathrm{HBO}$ : hyperbaric oxygen, WRS: word recognation score, HT: hypertension, HL: hyperlipidemia, DM: diabetes mellitus

rette usage, and additional diseases of both groups. There was no statistically significant difference between the two groups in terms of these indicated parameters $(p>0.05)$.

When patients with severe and severe hearing loss $(>60$ $\mathrm{dB})$ were evaluated separately, there were 104 patients in the Steroid + HBO group and 40 patients in the Steroid group. The pre-treatment PTA value was $82 \mathrm{~dB}$ in the Steroid $+\mathrm{HBO}$ group and the $88 \mathrm{~dB}$ in the Steroid group. The post-treatment PTA value was $54 \mathrm{~dB}$ in the Steroid+HBO group and $64 \mathrm{~dB}$ in the Steroid group. There was no statistically significant difference between groups in terms of the pre-treatment PTA values and hearing gains $(p>0.05)$ (Table 3 ).

When both treatment groups were grouped according to audiogram type, bowl type audiograms were not included in the evaluation due to the low number of patients. There was no statistically significant difference in hearing gain between the two groups in the descending, ascending, and flat type audiograms ( $p>0.05)$ (Table 4$)$. When considering the duration from the onset of ISSHL to the beginning of treatment, there was no significant difference in hearing gain in patients admitting between $1-3,4-10$, and after 10 days in both treatment groups $(p>0.05)$ (Table 5).

\section{Discussion}

Most ISSHL cases are idiopathic at presentation [9]. The treatment of ISSHL is highly controversial as the cause of the disease is unclear in many cases. Many theories have been proposed on the cause of ISSHL, some of which include vascular disorders, viral infections, immune disorders, labyrinth membrane rupture, metabolic dysfunction, and production of toxic substances $[3,10,11]$. Due to its multifactorial etiology, many agents are used for the treatment of ISSHL. Vasodilators, anticoagulants, corticosteroids, plasma expanders, antiviral therapies, vitamins, stellate ganglion blockers, and HBO therapy are among the most preferred treatment strategies $[12,13]$. Although several treatment regimens have been proposed, steroid therapy is the most commonly used and most effective pharmacological agent for ISSHL. It was also reported that over half of the patients received high-dose steroids during hospitalization [6,7]. HBO therapy was first reported to improve acute noise-induced hearing loss, sudden deafness, and peripheral vestibular disorders in the late 1960s [14]. HBO aims to improve microcirculation by increasing partial oxygen pressure and oxygen concentration in the inner ear for the treatment of ISSHL $[15,16]$.

There are many reports that HBO therapy has beneficial effects for the treatment of ISSHL $[6,10,12,17]$. Recent studies have also shown that addition of HBO to corticosteroid treatment may be beneficial in both acute acoustic trauma and ISSHL, especially when initiated early [18]. It was reported that HBO therapy was found to cause a significant improvement in PTA thresholds in ISSHL cases where primary corticosteroid therapy failed and were within 4 weeks of onset of hearing loss [17]. HBO therapy has beneficial effects when administered concomitantly with steroids in the early stages of the disease, and should be considered especially in patients with total or profound hearing loss $[6,10]$. In our study, $34.5 \%$ of patients in the Steroid $+\mathrm{HBO}$ group received HBO therapy within the first 3 days after the onset of hearing loss, and $87.6 \%$ of patients received treatment in the first 10 days. In 
Table 3. PTA values before and after the treatment, hearing gains and recovery rates (AAO-HNS Criteria) of the two groups at patients with severe and profound hearing loss

\begin{tabular}{|c|c|c|c|c|c|c|c|c|c|}
\hline \multirow[b]{2}{*}{$\begin{array}{l}\text { Treatment } \\
\text { groups }\end{array}$} & \multirow[b]{2}{*}{$\begin{array}{l}\text { Pre-treatment PTA } \\
\text { Mean } \pm \text { SD }(\mathrm{dB})\end{array}$} & \multirow[b]{2}{*}{$\begin{array}{c}\text { Post-treatment PTA } \\
\text { Mean } \pm \text { SD }(\mathrm{dB})\end{array}$} & \multirow[b]{2}{*}{$\begin{array}{c}\mathrm{P} \\
\text { value }\end{array}$} & \multirow[b]{2}{*}{$\begin{array}{l}\text { Hearing gain } \\
\text { Mean } \pm S D(d B)\end{array}$} & \multirow[b]{2}{*}{$\begin{array}{c}\mathrm{p} \\
\text { value }\end{array}$} & \multicolumn{3}{|c|}{ AAO-HNS Criteria $^{*}$} & \multirow[b]{2}{*}{$\begin{array}{c}\mathrm{p} \\
\text { value }\end{array}$} \\
\hline & & & & & & $\begin{array}{c}\text { Complete } \\
\text { recovery } \\
(\%)\end{array}$ & $\begin{array}{l}\text { Partial } \\
\text { recovery } \\
(\%)\end{array}$ & $\begin{array}{c}\text { No } \\
\text { recovery } \\
(\%)\end{array}$ & \\
\hline $\begin{array}{l}\text { Steroid } \\
\qquad(>60 \mathrm{~dB})(\mathrm{n}=40)\end{array}$ & $88.45 \pm 2.07$ & $64.50 \pm 4.36$ & $<0.001^{*}$ & $23.95 \pm 3.74$ & & $6(15)$ & $18(45)$ & $16(40)$ & \\
\hline $\begin{array}{l}\text { Steroid+HBO } \\
(>60 \mathrm{~dB})(\mathrm{n}=104)\end{array}$ & $82.45 \pm 1.47$ & $54.37 \pm 2.75$ & $<0.001^{*}$ & $28.07 \pm 2.46$ & 0.374 & $28(26.9)$ & $43(41.3)$ & $33(31.7)$ & 0.300 \\
\hline
\end{tabular}

Table 4. Hearing gain levels in both treatment modalities according to audiogram type

\begin{tabular}{lcc}
\hline \multicolumn{1}{c}{$\begin{array}{c}\text { Treatment group/ } \\
\text { type of audiogram }\end{array}$} & $\begin{array}{c}\text { Median } \\
\text { hearing gain }(\mathrm{dB})\end{array}$ & p value \\
\hline Steroid/descending $(\mathrm{n}=17)$ & $16.88 \pm 2.59$ & 0.908 \\
Steroid+HBO/descending $(\mathrm{n}=32)$ & $15.06 \pm 2.93$ & \\
Steroid/ascending $(\mathrm{n}=14)$ & $20.42 \pm 1.92$ & 0.254 \\
Steroid+HBO/ascending $(\mathrm{n}=37)$ & $17.75 \pm 2.75$ & \\
Steroid/flat $(\mathrm{n}=44)$ & $23.21 \pm 3.27$ & 0.993 \\
Steroid+HBO/flat $(\mathrm{n}=114)$ & $23.53 \pm 2.31$ & \\
\hline
\end{tabular}

Mann-Whitney U test. HBO: hyperbaric oxygen

Table 5. Hearing gain levels in both treatment modalities by time of application

\begin{tabular}{lcc}
\hline \multicolumn{1}{c}{$\begin{array}{c}\text { Treatment group/ } \\
\text { application time }\end{array}$} & $\begin{array}{c}\text { Median } \\
\text { hearing gain }(\mathrm{dB})\end{array}$ & p value \\
\hline Steroid/ $1-3$ days $(\mathrm{n}=32)$ & $28.93 \pm 3.70$ & 0.544 \\
Steroid $+\mathrm{HBO} / 1-3$ days $(\mathrm{n}=67)$ & $27.11 \pm 3.13$ & \\
Steroid/4-10 days $(\mathrm{n}=34)$ & $16.08 \pm 2.59$ & 0.356 \\
Steroid $+\mathrm{HBO} / 4-10$ days $(\mathrm{n}=103)$ & $19.66 \pm 1.89$ & \\
Steroid/ $>10$ days $(\mathrm{n}=12)$ & $15.91 \pm 3.76$ & 0.344 \\
Steroid+HBO/>10 days $(\mathrm{n}=24)$ & $10.62 \pm 3.64$ & \\
\hline
\end{tabular}

Mann-Whitney U test. HBO: hyperbaric oxygen

general, most of our patients started HBO therapy during the early disease stage. Therefore, the lack of a significant difference in hearing gain between the two groups cannot be attributed to delayed HBO therapy in this study.

Although many prognostic factors have been identified for ISSHL, the consensus on this is incomplete. Profound hearing loss, advanced age, delay in treatment, presence of comorbidities, and audiogram type are some of the prognostic factors of ISSHL. A descending type audiogram negatively affects the prognosis, whereas patients with an ascending audiogram have been reported to be associated with a better prognosis [19]. In this study, we did not examine the difference between audiogram types in terms of hearing gain. However, when we separated the patients according to audiogram types, we examined whether there was a difference between the two treat- ment methods. Consequently, there was no significant difference in the descending, ascending, and flat audiogram types between the two groups in terms of recovery. Similarly, we divided patients into three groups based on the duration between the onset of hearing loss and treatment. There was no significant difference between the groups in terms of hearing gain during all three time periods. At this point, it is unclear whether there is a difference between the two treatment methods according to the time of admission and audiometry type, or whether a decision on the choice of treatment can be made in the light of these parameters. We were only able to evaluate the two groups based on the gain in hearing. When we divided patients into subgroups, we could not make a comparison according to the recovery rate due to the low number of patients in the steroid subgroups. Therefore, this is alimitation of this study, and we believe that further studies need to be conductedon this subject.

In a study, considering the degree of hearing loss, they found that the rate of improvement in hearing was significantly higher in the Steroid+HBO group compared to the Steroid group in patients with an initial hearing level of $80 \mathrm{~dB}$ and above; therefore, HBO should be used in such patients [12]. However, although many studies have reported that adding HBO to steroid treatment provides additional benefits, there have also been some reports claiming the opposite. In a study comparing three different treatment modalities in ISSHL, it was indicated that although the response rate to oral steroid and oral Steroid $+\mathrm{HBO}$ treatment was $50.8 \%$ and $61.5 \%$, respectively, there was no significant difference between these two groups in terms of response to treatment [20]. In a recent study, comparing oral+IT steroid and oral + IT steroid + HBO therapies in ISSHL patients with severe and profound hearing loss $(>70 \mathrm{~dB})$, the addition of HBO to steroid combination therapy did not improve the mean PTA values. However, in the same study, they reported that the addition of HBO was beneficial for improving low-frequency hearing and word discrimination scores [21]. In our study, when the patients with 
severe and profound hearing loss $(>60 \mathrm{~dB})$ were evaluated separately, there was no significant difference between the two treatment groups in terms of both hearing gain and recovery rate. We speculate that this may be due to the fact that steroid treatment was used in combination and not alone, which could be considered as an intensive steroid treatment. This could explain the lack of a significant difference between the two groups. However, considering the average hearing gain of $24 \mathrm{~dB}$ in the steroid group and $28 \mathrm{~dB}$ in the $\mathrm{HBO}$ group in patients with severe and profound hearing loss, we did not consider this improvement to be significant in both groups. Therefore, although we found no difference between the two groups, we believe that HBO should be considered as a treatment strategy in this patient group, especially for severe and profound hearing loss. In a review conducted in 2018, it was reported that adding $\mathrm{HBO}$ to steroid treatment may be beneficial in cases of severe and profound hearing impairment [22]. The guideline for clinical practice for ISSHL, which was updated this year, states that HBO can be administered as the initial therapy in combination with steroids within the first two weeks of onset, or as salvage therapy within the first month [23].

In conclusion, in this study, there was no significant difference in terms of hearing gain and degree of recovery between the steroid and Steroid+HBO groups in ISSHL patients. Furthermore, there was no significant difference between the two groups in the patients with severe and profound hearing loss. Hearing gain was similar when evaluated by audiogram type and admission time in both treatment groups. In conclusion, we found that the addition of HBO therapy to systemic and IT steroid treatment did not affect hearing gain at all degrees of hearing loss at this study.

\section{Acknowledgments \\ None}

\section{Conflicts of interest}

The authors have no financial conflicts of interest.

\section{Author Contributions}

Conceptualization: all authors. Data Curation: all authors. Formal Analysis: Abitter Yücel. Funding Acquisition: all authors. Investigation: all authors. Methodology: all authors. Project Administration: all authors. Resources: all authors. Software: all authors. Supervision: all authors. Validation: all authors. Visualization: all authors. Writing original draft: all authors. Writing — review \& editing: all authors. Approval of final manuscript: all authors.

\section{ORCID iDs}

Abitter Yücel

Yaşar Özbuğday

https://orcid.org/0000-0002-6433-0362

https://orcid.org/0000-0001-6735-5656

\section{REFERENCES}

1) Byl FM Jr. Sudden hearing loss: eight years' experience and suggested prognostic table. Laryngoscope 1984;94(5 Pt 1):647-61.

2) Haberkamp TJ, Tanyeri HM. Management of idiopathic sudden sensorineural hearing loss. Am J Otol 1999;20:587-92; discussion 593-5.

3) Eisenman D, Arts HA. Effectiveness of treatment for sudden sensorineural hearing loss. Arch Otolaryngol Head Neck Surg 2000;126: 1161-4.

4) Quaranta N, Ramunni A, De Luca C, Brescia P, Dambra P, De Tullio $\mathrm{G}$, et al. Endothelial progenitor cells in sudden sensorineural hearing loss. Acta Otolaryngol 2011;131:347-50.

5) Toroslu T, Erdoğan H, Çağlar Ö, Güçlü O, Dereköy FS. Comparison of different treatment methods for idiopathic sudden sensorineural hearing loss. Turk Arch Otorhinolaryngol 2018;56:226-32.

6) Körpinar S, Alkan Z, Yiğit O, Gör AP, Toklu AS, Cakir B, et al. Factors influencing the outcome of idiopathic sudden sensorineural hearing loss treated with hyperbaric oxygen therapy. Eur Arch Otorhinolaryngol 2011;268:41-7.

7) Labus J, Breil J, Stützer H, Michel O. Meta-analysis for the effect of medical therapy vs. placebo on recovery of idiopathic sudden hearing loss. Laryngoscope 2010;120:1863-71.

8) Stachler RJ, Chandrasekhar SS, Archer SM, Rosenfeld RM, Schwartz SR, Barrs DM, et al. Clinical practice guideline: sudden hearing loss. Otolaryngol Head Neck Surg 2012;146(3 Suppl):S1-35.

9) Rauch SD. Clinical practice. Idiopathic sudden sensorineural hearing loss. N Engl J Med 2008;359:833-40.

10) Topuz E, Yigit O, Cinar U, Seven H. Should hyperbaric oxygen be added to treatment in idiopathic sudden sensorineural hearing loss? Eur Arch Otorhinolaryngol 2004;261:393-6.

11) Stokroos RJ, Albers FW. The etiology of idiopathic sudden sensorineural hearing loss. A review of the literature. Acta Otorhinolaryngol Belg 1996;50:69-76.

12) Fujimura T, Suzuki H, Shiomori T, Udaka T, Mori T. Hyperbaric oxygen and steroid therapy for idiopathic sudden sensorineural hearing loss. Eur Arch Otorhinolaryngol 2007;264:861-6.

13) Suzuki H, Hashida K, Nguyen KH, Hohchi N, Katoh A, Koizumi H, et al. Efficacy of intratympanic steroid administration on idiopathic sudden sensorineural hearing loss in comparison with hyperbaric oxygen therapy. Laryngoscope 2012;122:1154-7.

14) Appaix A, Demard F. [Hyperbaric oxygenotherapy and sudden perceptive deafness]. Rev Laryngol Otol Rhinol (Bord) 1970;91:951-72.

15) Lamm K, Lamm H, Arnold W. Effect of hyperbaric oxygen therapy in comparison to conventional or placebo therapy or no treatment in idiopathic sudden hearing loss, acoustic trauma, noise-induced hearing loss and tinnitus. A literature survey. Adv Otorhinolaryngol 1998; 54:86-99.

16) Goto F, Fujita T, Kitani Y, Kanno M, Kamei T, Ishii H. Hyperbaric oxygen and stellate ganglion blocks for idiopathic sudden hearing loss. Acta Otolaryngol 1979;88:335-42.

17) Pezzoli M, Magnano M, Maffi L, Pezzoli L, Marcato P, Orione M, et al. Hyperbaric oxygen therapy as salvage treatment for sudden sensorineural hearing loss: a prospective controlled study. Eur Arch Otorhinolaryngol 2015;272:1659-66.

18) Bayoumy AB, de Ru JA. The use of hyperbaric oxygen therapy in acute hearing loss: a narrative review. Eur Arch Otorhinolaryngol 2019;276:1859-80.

19) Edizer DT, Çelebi Ö, Hamit B, Baki A, Yiğit Ö. Recovery of idiopathic sudden sensorineural hearing loss. J Int Adv Otol 2015;11:122-6.

20) Ergun Taşdöven G, Derin AT, Yaprak N, Özçağlar HÜ. The place of hyperbaric oxygen therapy and ozone therapy in sudden hearing loss. Braz J Otorhinolaryngol 2017;83:457-63.

21) Cho I, Lee HM, Choi SW, Kong SK, Lee IW, Goh EK, et al. Comparison of two different treatment protocols using systemic and intratympanic steroids with and without hyperbaric oxygen therapy in patients with severe to profound idiopathic sudden sensorineural hearing 
loss: a randomized controlled trial. Audiol Neurootol 2018;23:199207.

22) Eryigit B, Ziylan F, Yaz F, Thomeer HGXM. The effectiveness of hyperbaric oxygen in patients with idiopathic sudden sensorineural hearing loss: a systematic review. Eur Arch Otorhinolaryngol 2018;
275:2893-904.

23) Chandrasekhar SS, Tsai Do BS, Schwartz SR, Bontempo LJ, Faucett EA, Finestone SA, et al. Clinical Practice Guideline: Sudden Hearing Loss (Update). Otolaryngol Head Neck Surg 2019;161(1_ suppl):S1-45. 